\title{
Modeling of pollutants from artisanal refining of crude oil in Port Harcourt: A case study of Eagle Island
}

\author{
Adeloye Olalekan Michael ${ }^{*}$ and Ekade Padiowei Joepen \\ Department of Chemical/Petrochemical Engineering, Rivers State University, Port Harcourt-Nigeria.
}

World Journal of Advanced Engineering Technology and Sciences, 2021, 02(01), 034-044

Publication history: Received on 08 January 2021; revised on 10 February 2021; accepted on 12 February 2021

Article DOI: https://doi.org/10.30574/wjaets.2021.2.1.0013

\begin{abstract}
Air sampling was carried out on the research area (Eagle Island) using both experimental and Gaussian dispersion model. A DM 106(particulate mass monitor) was applied to deduce the concentrations of suspended particulate matters (PM 1, PM 2.5, PM 10). Also, concentrations of pollutants $\left(\mathrm{NO}_{2}, \mathrm{VOCs}, \mathrm{SO}_{2}\right)$ were obtained using an Aerqual 300 device, while temperature, humidity, wind speed and wind direction were measured using Portable extech 45156 weather station and compass with experimental values obtained for two days (morning and night). Thus, these experimental concentration values obtained was plotted showing level of concentration at different locations (distances). In addition, Gaussian dispersion model was used to predict pollution concentration at various distances to ascertain the level of pollution within the research study area. Modeled results obtained was compared with experimental values to evaluate deviations, and a GIS based model (ARCGIS) was used to determine the general mapping of the research study area with dispersion of pollutants from source to distance up to $1000 \mathrm{~m}$ depicted.
\end{abstract}

Keywords: Artisanal refinery; Pollutant gases; Suspended particulate matters; Eagle Island (Port Harcourt); Gaussian dispersion model

\section{Introduction}

The upsurge of oil theft in the Port Harcourt metropolis in recent times is alarming. Currently, Nigeria is losing over 300,000 barrels of crude oil per day to oil theft. Thus, oil theft and illegal bunkering activities in the Port Harcourt pose a challenge that threatens the very foundation of the oil industry and national economy [1]. Air pollution is the introduction of chemicals, particulate matters or biological materials from such illegal bunker to the atmosphere. This air pollution causes damage to the natural environment or built environment into the atmosphere. It can be defined as the presence in the outdoor or indoor atmosphere of the one or more gaseous or particulate contaminations in quantities, characteristics and of duration such as to be injurious to human, plant or animal life or to property, or which unreasonably interferes with the comfortably enjoyment of life and property [5]. It has been difficult to achieve cooperation for air pollution control in developing countries like Nigeria, whose main concern is to provide such basis need as food, shelter and employment for her populace [1].

Sampling is a proper technique use to acquire a representative sample of possible contaminated air or gas for later evaluation or analysis of the quantity of pollutants present. The goal of air sampling is to accurately assess the impact of a contaminant source on ambient air quality. This impact is expressed in terms of overall average or maximum air concentrations for the time period of concern and may be affected by the transport and release of pollutants from both on and off-site sources. The location of these sources must be taken into account as they impact the selection of sampling site. Unlike soil and groundwater concentrations, air concentrations at points of interest can easily vary by orders of magnitude over the period of concern [2]. This variability plays a major role in designing an air sampling plan.

\footnotetext{
${ }^{*}$ Corresponding author: Adeloye Olalekan Michael

Department of Chemical/Petrochemical Engineering, Rivers State University, Port Harcourt-Nigeria.
} 
Downwind air concentration is determined by the amount of material being released from the site into the air (the emission rate) and by the degree that the contamination is diluted as it is transported. Local meteorology and topography govern downwind dilution process. Contaminants emission rates can also be heavily influenced by onsite meteorology and on-site activities, thus all of these concerns must be incorporated into an air sampling plan [3]. A sampling strategy can be simple or complex, depending on the sampling program objectives. Programs involving characterization of the pollutant contribution from a single point source tend to be simple, whereas sampling programs investigating fate and transport characteristics of components from diverse sources require a more complex sampling strategy [4]

During illegal refining processes, the liquid crude oil turns into gaseous substance and contaminate the atmosphere, because the process did not follow the principles of fractional distillation and non-availability of modern thermodynamic equipment. This research study focused on the upwards substances from the emitted gases in the atmosphere. The crude oil boils in the bunker machine or illegal refinery and exposed the both wanted and unwanted gases to the atmosphere [6].

However, Artisanal refining is the process of procuring stolen crude oil and in refining them in the so-called bush refineries with the use of local resources and skills. The basic materials typically involves rudimentary illegal stills often metal pipes and drums welded together in which crude oil is boiled and the resultant fumes are collected, cooled and condensed in tanks to be used locally for lighting, energy or transport. The basic refining technique first used during the Nigerian Civil War was resurrected and modernized by members of militant camps between 2005 and 2009 , providing fuel and cash to support the Niger Delta's aspiration. After an amnesty deal for militants was brokered in 2009 by the Nigeria government, the militants returned to their villages, taking their knowledge of refining with them. As a result of the failure to prevent this at an early stage and the huge commercial rewards attached, the trade grew and became more entrenched in the community [3].

On the average, typical artisanal refinery produces about forty to sixty drums of diesel per day, and sites vary in size and reflect different levels of investment. Small scale sites tend to attract women and people with very low levels of capital to invest, whilst larger scale sites involve entrepreneurs who own relatively large production sites. Severe damage is done to the environment as a result of artisanal refining. The refining process leads to a significant quantity of wastage being dumped in rivers and streams or on land. Two drums of crude oil translate into one drum of product once refined and the distilleries are heated on open fires fed by crude oil that is tipped into pits in the ground. As a reasonable quantity of the oil burns away, some seeps into the ground during the process of refining, and the resulting oil spills from broken pipes and wastes from tens of thousands of makeshift refineries combine to produce enormous environmental pollution on land and in the water. Apart from the high risk of self-harm from artisanal refining a large number of accidents, fires and explosions occur [3].

In addition, one of the main environmental problems of Nigeria is the burning of associated gas in flares during refining operations. Flare systems of oil refineries have a serious impact on the air quality in industrial area and urban localities in the vicinity of industrial refining complex, subsequently air temperature increase and air is polluted due to emitted gases from refining of hydrocarbons and other fractional distillation process [1].

Estimation of the degree of pollution in the atmosphere by pollutants such as $\mathrm{SO}_{2}, \mathrm{NO}_{2}, \mathrm{CO}, \mathrm{CO}_{2}$ etc is a major problem to Port-Harcourt residents and its environs. Atmospheric pollution of the territory under which this illegal refineries are constructed is now a menace to human lives in the city. An Assessment is needed to combat this issue that is fast becoming pandemic to Port-Harcourt and its environs, and the process of combating this menace is the development of predictive model. The areas where these illegal refineries are located will be having harmful substances emitted at all times because of improper refining of petroleum products. Some of the products would be raw due to incomplete processing and others would be flared especially the gases [2]. Therefore, the aim of this research study is to measure and model pollutants from artisanal refining of crude oil in Port-Harcourt metropolis using Eagle Island as a case study. This aim will be achieved by determining the impact of various pollutants such as $\mathrm{CO}_{2}, \mathrm{NO}_{2}, \mathrm{SO}_{2}$ with their concentrations at various distance known, modeling of observed values ( $\mathrm{NO}_{2}, \mathrm{VOC}, \mathrm{SO}_{2}$, and $\mathrm{CO}$ ) to show distribution or dispersion rate, develop a model that can account for the pollutants in the substances emitted during the refining processes, and ascertain the level of suspended particulate matter (SPM) that accompanied the pollutant during artisanal refining of crude oil in Port-Harcourt metropolis.

\section{Material and methods}

The following materials are applied for performing this research study, Aerqual 300, DM 106-Particulate Mass Monitor, Portable Extech 45156 Weather Station, Compass and GIS Based Model using ARCGIS. 


\subsection{Research Methods}

Particulate Matters (PM1, PM2.5, PM 10) Data Collection: A DM 106 particulate mass monitor was used to measure the particulate mass matter, and equipment was held at $1.5 \mathrm{~m}$ above ground level, ensuring the efficiency of the machine by detecting what an average human can inhale at that height and avoiding dust storm from the ground. The equipment sensor was held towards the prevailing wind. At stability of the sensor of the equipment, pollutants from artisanal refining of crude oil in Port Harcourt was measured.

$\mathrm{NO}_{2}$, VOCs, $\mathrm{SO}_{2}$ Data Collection: An aerqual 300 series was used for this measurement; the sensor was placed on the height of about $1.5 \mathrm{~m}$ above ground level to avoid contaminants from the ground. The sensor was placed in the direction of the prevailing wind, and after three minutes of warming up of sensors, results were displayed.

Meteorology: A portable extech 45156 weather station equipment was used to measure humidity, temperature, windspeed while the wind direction was detected by a compass.

\subsection{Gaussian Dispersion Model}

The following assumption were applied in modeling pollutants from artisanal refining process by using Gaussian dispersion model

Mass transfer in direction, this out shadows the contribution due to mass diffusion, assuming steady state solution to the dispersion of the pollutions in the atmosphere therefore, $\left[d_{-} c / d_{-} t=0\right]$

$\operatorname{speed}(\mathrm{u})$ is assumed constant

Major transport direction due to wind is at x-axis therefore Dx, Dy and Dz are constant

The Gaussian dispersion model based on the underlying assumptions above yields

$\left.\mathrm{U}\left(\mathrm{d}_{-} \mathrm{c} / \mathrm{dx}\right)=\mathrm{D}_{-} \mathrm{y}\left(\left(\mathrm{d}^{\wedge} 2 \mathrm{C}\right) / \llbracket \mathrm{dy}\right) \wedge^{\wedge} 2\right)+\mathrm{Dz}\left(\left(\mathrm{d}^{\wedge} 2 \mathrm{C}\right) / \llbracket \mathrm{dy} \rrbracket \wedge 2\right)$

Algebraic analysis of the Gaussian dispersion model equation and upon variable separation yields

$\mathrm{C}(\mathrm{x}, \mathrm{y}, \mathrm{z})=\mathrm{Q} / 2 \pi \mathrm{USySz} \quad\left[\exp -\left(\mathrm{z}^{\wedge} 2 / \mathrm{Dy}\right)\right]\left\{\exp [\llbracket-(\mathrm{z}-\mathrm{H}) \rrbracket \wedge 2 / \llbracket 2 \mathrm{dz} \rrbracket \wedge 2]+\exp \left[\llbracket-(\mathrm{z}-\mathrm{H}) \rrbracket^{\wedge} 2 / \llbracket 2 \sigma \mathrm{z} \rrbracket \wedge 2\right]\right\}$

Where;

$C(x, y, z)=$ mean concentration of diffusing substance at a point $(x, y, z)[m / m 3]$

$\mathrm{x}=$ downwind distance $[\mathrm{m}]$

$\mathrm{y}=$ crosswind distance $[\mathrm{m}]$

$\mathrm{z}=$ vertical distance above ground $[\mathrm{m}]$

$\mathrm{Q}=$ contaminant emission rate $[$ mass $/ \mathrm{s}]$

$\mathrm{D}=$ lateral dispersion coefficient function $[\mathrm{m}]$,

$\delta \_\mathrm{y}=$ vertical dispersion coefficient function [m]

$\delta \_z=$ mean wind velocity in downwind direction $[\mathrm{m} / \mathrm{s}]$

$\mathrm{H}=$ effective stack height $[\mathrm{m}]$. 


\section{Results and discussion}

Morning and night air qualities were carried out through the concentration in gases of air quality parameters with (PM

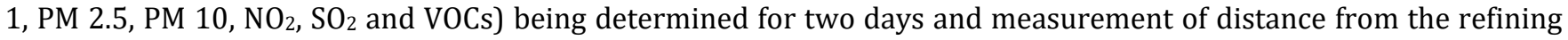
source for each day noted. The air quality results is shown in Tables and Figures thus.

Table 1 Concentration of Air Quality Parameters for Day 1 (Morning)

\begin{tabular}{|l|l|l|l|}
\hline Distance $\mathbf{( m )}$ & $\begin{array}{l}\text { Concentration of } \mathbf{N}_{2} \\
\left(\mathbf{m g} / \mathbf{m}^{\mathbf{3}} \mathbf{)}\right.\end{array}$ & $\begin{array}{l}\text { Concentration of } \mathbf{S O}_{\mathbf{2}} \\
\left(\mathbf{m g} / \mathbf{m}^{\mathbf{3}} \mathbf{)}\right.\end{array}$ & $\begin{array}{l}\text { Concentration of VOC } \\
\left(\mathbf{m g} / \mathbf{m}^{\mathbf{3}} \mathbf{)}\right.\end{array}$ \\
\hline 50 & 0.032 & 0.060 & 179.100 \\
\hline 100 & 0.046 & 0.020 & 81.100 \\
\hline 200 & 0.028 & 0.010 & 63.100 \\
\hline 300 & 0.790 & 0.010 & 61.100 \\
\hline 400 & 0.059 & 0.0 & 49.200 \\
\hline 1000 & 0.059 & 0.0 & 45.0 \\
\hline
\end{tabular}

Table 2 Concentration of Air Quality Parameters for Day 1 (Night)

\begin{tabular}{|l|l|l|l|}
\hline Distance $(\mathbf{m})$ & $\begin{array}{l}\text { Concentration of } \mathbf{N O}_{2} \\
\left(\mathbf{m g} / \mathbf{m}^{\mathbf{3}} \mathbf{)}\right.\end{array}$ & $\begin{array}{l}\text { Concentration of } \mathbf{S 0}_{\mathbf{2}} \\
\left(\mathbf{m g} / \mathbf{m}^{\mathbf{3}} \mathbf{)}\right.\end{array}$ & $\begin{array}{l}\text { Concentration of VOC } \\
\left(\mathbf{m g} / \mathbf{m}^{\mathbf{3}} \mathbf{)}\right.\end{array}$ \\
\hline 50 & 0.041 & 0.050 & 116.100 \\
\hline 100 & 0.043 & 0.020 & 64.800 \\
\hline 200 & 0.007 & 0.010 & 61.100 \\
\hline 300 & 0.080 & 0.010 & 64.100 \\
\hline 400 & 0.052 & 0.0 & 62.300 \\
\hline 1000 & 0.031 & 0.0 & 46.600 \\
\hline
\end{tabular}
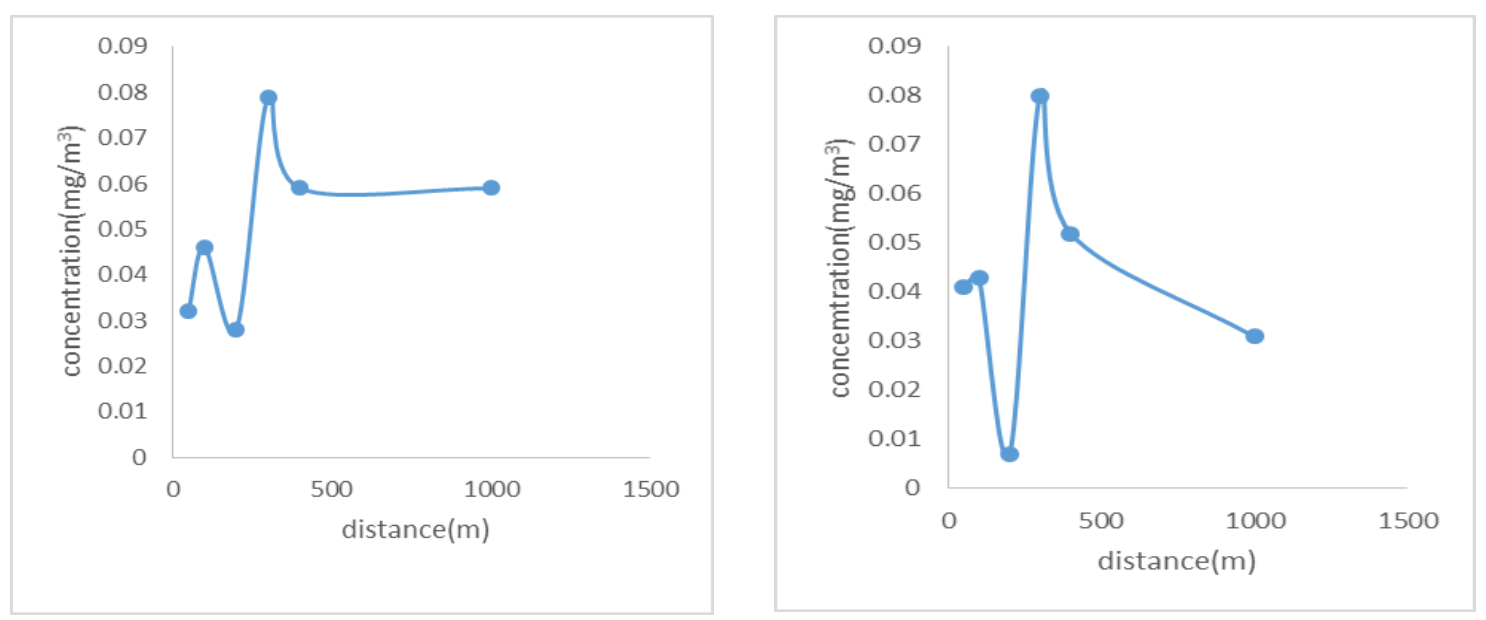

Figure 1 Plots of $\mathrm{NO}_{2}$ against Distance for Day One (Morning and night)

The plot shows highest level of concentration of $\mathrm{NO}_{2}$ at $300 \mathrm{~m}$ and lowest level of concentration observed at $200 \mathrm{~m}$ for both morning and night analysis. 
World Journal of Advanced Engineering Technology and Sciences, 2021, 02(01), 034-044
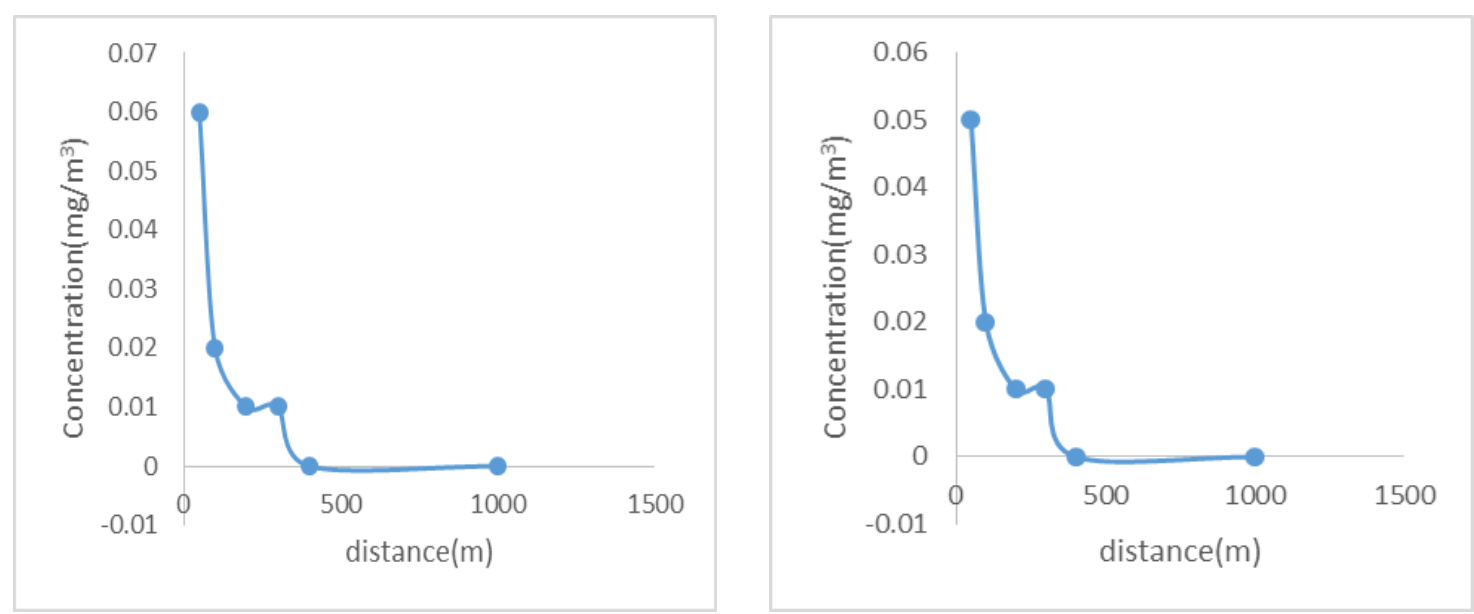

Figure 2 Plot of $\mathrm{SO}_{2}$ against Distance Day One (Morning and Night)

From the plot above, highest level of concentration of $\mathrm{SO}_{2}$ is at $50 \mathrm{~m}$ and a decline in concentration was observed up to the $1 \mathrm{~km}$ distance. $\mathrm{SO}_{2}$ was at minimal level at $400 \mathrm{~m}$ and $1 \mathrm{~km}$ distances respectively.
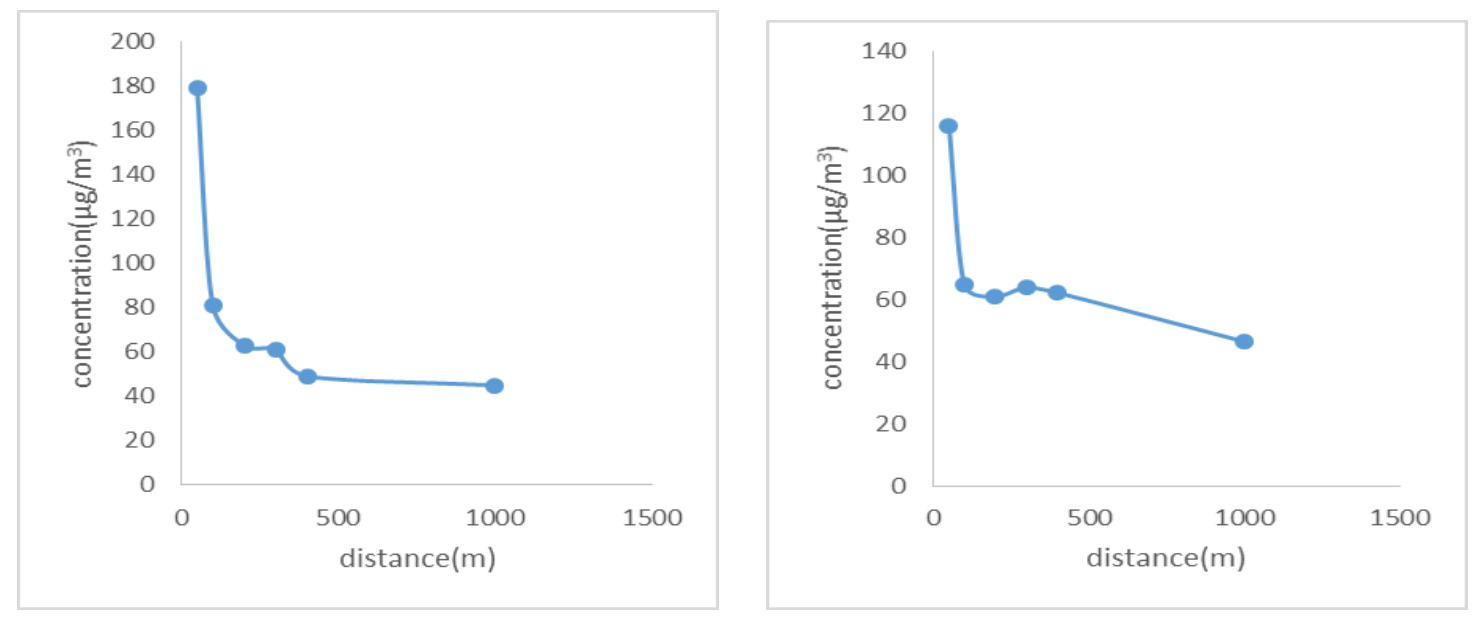

Figure 3 Plot of VOCs Concentration against Distance Day One (Morning and Night)

The plot shows a decline in concentration of VOCs with distance. At $50 \mathrm{~m}$ from artisanal refining point, highest level of concentration of VOCs was obtained and at $1 \mathrm{~km}$ lowest value of VOCs concentration was observed for both day and night.

Table 3 Concentration of Air Quality Parameters for Day 2 (Morning)

\begin{tabular}{|l|l|l|l|}
\hline Distance $(\mathbf{m})$ & $\begin{array}{l}\text { Concentration of } \mathbf{N O}_{2} \\
\left(\mathbf{m g} / \mathbf{m}^{3} \mathbf{)}\right.\end{array}$ & $\begin{array}{l}\text { Concentration of } \mathbf{S O}_{\mathbf{2}} \\
\left(\mathbf{m g} / \mathbf{m}^{\mathbf{3}}\right)\end{array}$ & $\begin{array}{l}\text { Concentration of VOC } \\
\left(\mathbf{m g} / \mathbf{m}^{3} \mathbf{)}\right.\end{array}$ \\
\hline 50 & 0.041 & 0.050 & 116.100 \\
\hline 100 & 0.045 & 0.020 & 66.900 \\
\hline 200 & 0.007 & 0.020 & 61.100 \\
\hline 300 & 0.086 & 0.010 & 62.300 \\
\hline 400 & 0.052 & 0.0 & 45.100 \\
\hline 1000 & 0.031 & 0.0 & 47.600 \\
\hline
\end{tabular}


Table 4 Concentration of Air Quality Parameters for Day 2 (Night)

\begin{tabular}{|c|c|c|c|}
\hline Distance (m) & $\begin{array}{l}\text { Concentration of } \mathrm{NO}_{2} \\
\left(\mathrm{mg} / \mathrm{m}^{3}\right)\end{array}$ & $\begin{array}{l}\text { Concentration of } \mathrm{SO}_{2} \\
\left(\mathrm{mg} / \mathrm{m}^{3}\right)\end{array}$ & $\begin{array}{l}\text { Concentration of VOC } \\
\left(\mathrm{mg} / \mathrm{m}^{3}\right)\end{array}$ \\
\hline 50 & 0.041 & 0.050 & 116.100 \\
\hline 100 & 0.045 & 0.020 & 64.800 \\
\hline 200 & 0.007 & 0.020 & 61.100 \\
\hline 300 & 0.086 & 0.010 & 64.100 \\
\hline 400 & 0.052 & 0.0 & 62.300 \\
\hline 1000 & 0.031 & 0.0 & 46.600 \\
\hline
\end{tabular}
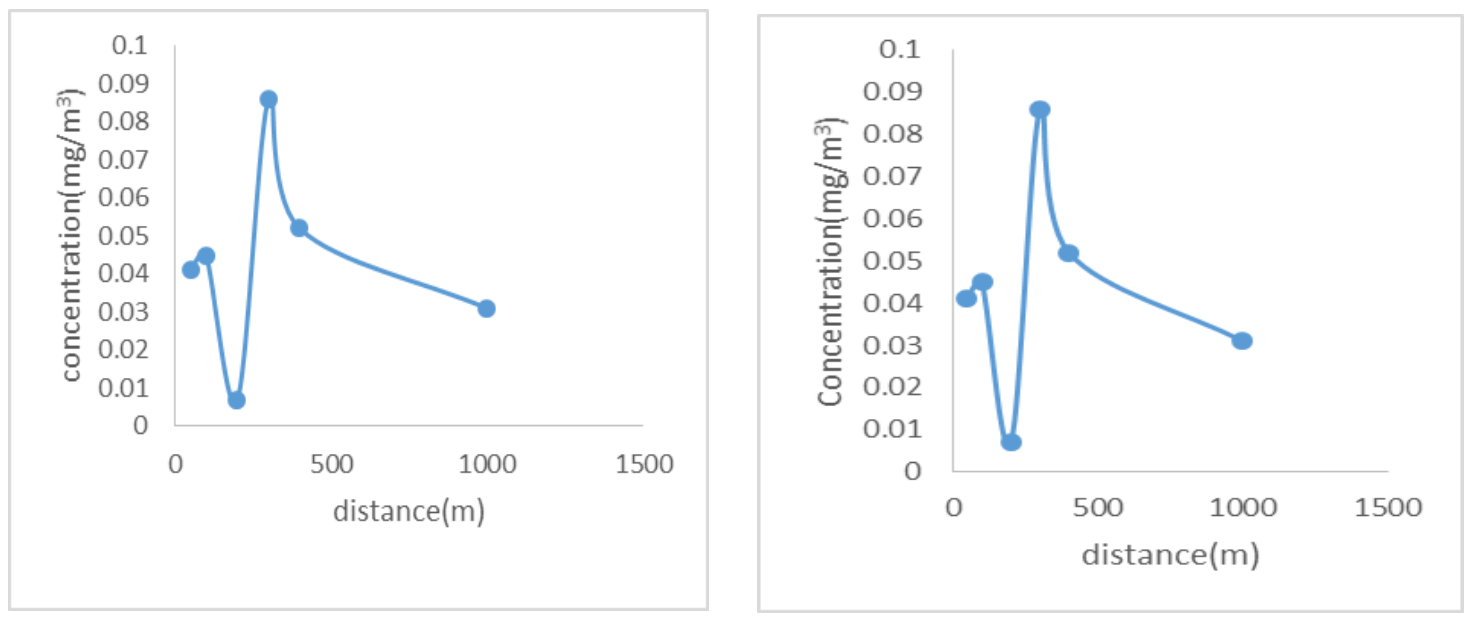

Figure 4 Plot of $\mathrm{NO}_{2}$ Concentration against Distance Day Two (Morning and Night)

The morning plot showed that the farthest distance from artisanal refining point, the lowest concentration of $\mathrm{NO}_{2}$ observed and there is variations in $\mathrm{NO}_{2}$ values at $100 \mathrm{~m}, 200 \mathrm{~m}$, and $300 \mathrm{~m}$ respectively due to wind directions and other factors affecting dispersion of pollutants. The highest level of concentration is achieved at $200 \mathrm{~m}$ distance for morning analysis. Also, night plot shows that $300 \mathrm{~m}$ has the highest concentration level at $0.086(\mathrm{mg} / \mathrm{m} 3)$ of the pollutant and decreases gradually.
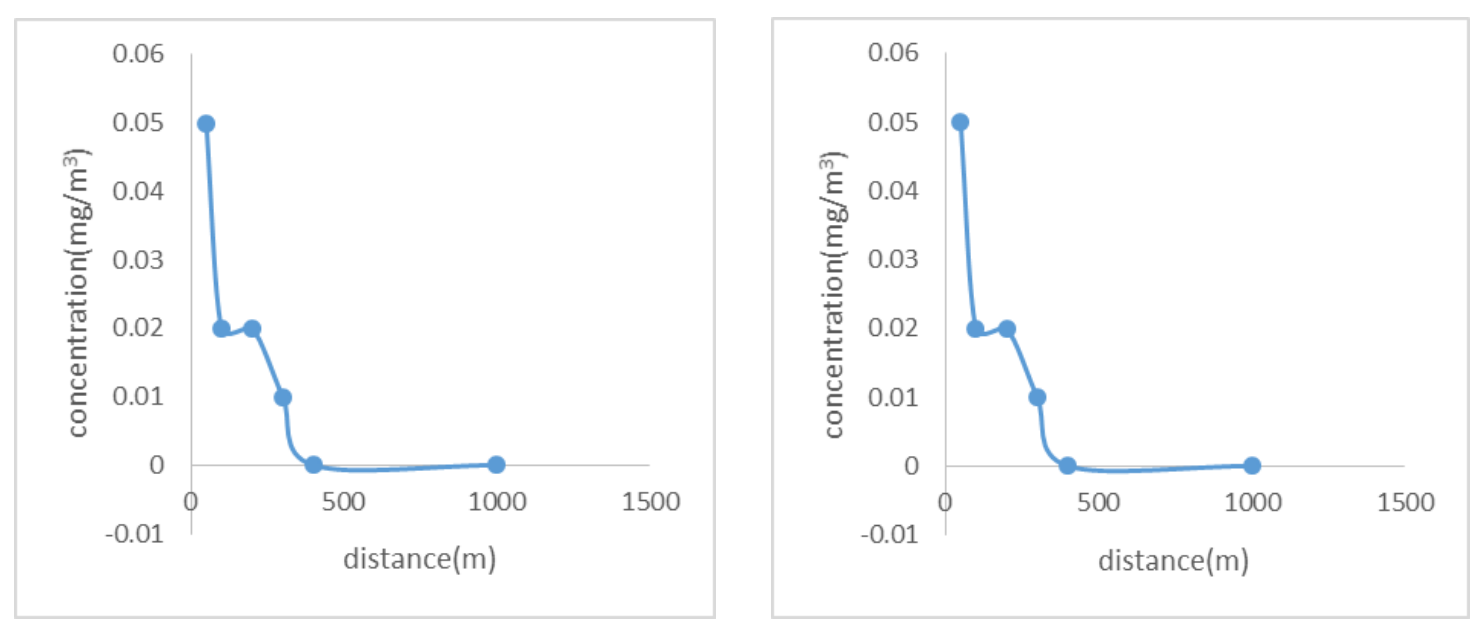

Figure 5 Plot of $\mathrm{SO}_{2}$ Concentration against Distance Day Two (Morning and Night) 
The plot shows little traces of $\mathrm{SO}_{2}$ across various distances but $\mathrm{SO}_{2}$ was completely absent in the atmosphere at $400 \mathrm{~m}$ and $1000 \mathrm{~m}$ respectively. The nearest distance to the refining point of $50 \mathrm{~m}$ yielded the highest concentration of $\mathrm{SO}_{2}$ in both morning and night analysis.
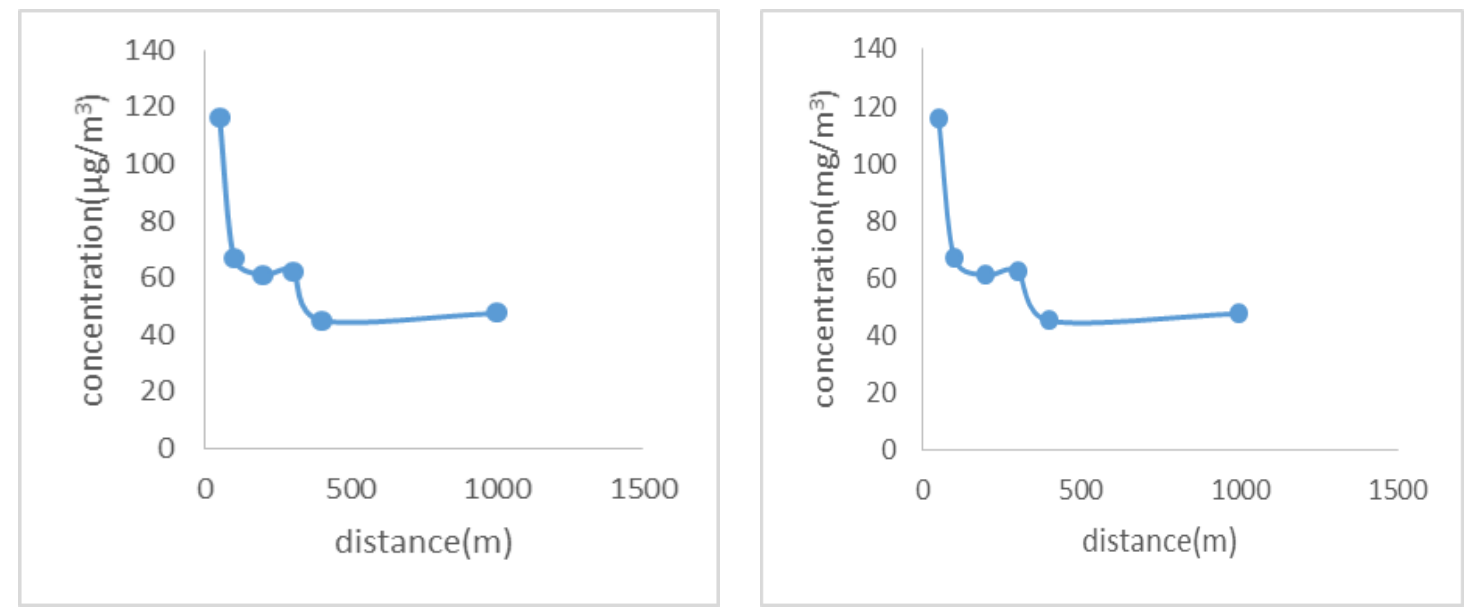

Figure 6 Plot of VOCs Concentration against Distance Day two (Morning and Night)

Figure 6 shows highest concentration at $50 \mathrm{~m}$ due to its proximity to the source but it declines at $100 \mathrm{~m}$ and $200 \mathrm{~m}$ respectively and a slight increase in concentration level at $300 \mathrm{~m}$ and $400 \mathrm{~m}$ for morning analysis. In addition, heavy concentration of VOCs at $50 \mathrm{~m}$ during the night but lowest level of concentration at $400 \mathrm{~m}$ as opposed to morning analysis. The plot shows greater concentration of the pollutant at $1000 \mathrm{~m}$ than $400 \mathrm{~m}$ due to wind movement during the night with a decline in concentration from source, at $100 \mathrm{~m}$ and $200 \mathrm{~m}$ respectively.

\subsection{Suspended Particulate Matters}

The suspended particulate matters concentration for two days (morning and night) were determined through the application of Geographic Information System (GIS). The suspended particulate matters data for the research study is presented thus.

Table 5 Suspended Particulate Matters for Day 1

\begin{tabular}{|l|l|l|l|l|l|l|}
\hline \multirow{2}{*}{ Location (m) } & \multicolumn{3}{|l|}{ Morning $\left(\boldsymbol{\mu g} / \mathbf{m}^{3}\right)$} & \multicolumn{3}{l|}{ Night $\left(\boldsymbol{\mu g} / \mathbf{m}^{3}\right)$} \\
\cline { 2 - 7 } & PM 1 & PM 2.5 & PM 10 & PM 1 & PM 2.5 & PM 10 \\
\hline 50 & 11.0 & 21.0 & 27.0 & 13.0 & 22.0 & 29.0 \\
\hline 100 & 16.0 & 25.0 & 30.0 & 15.0 & 26.0 & 34.0 \\
\hline 200 & 11.0 & 17.0 & 26.0 & 9.0 & 18.0 & 27.0 \\
\hline 300 & 7.0 & 12.0 & 14.0 & 8.0 & 13.0 & 14.0 \\
\hline 400 & 7.0 & 12.0 & 17.0 & 6.0 & 12.0 & 14.0 \\
\hline 1000 & 8.0 & 15.0 & 14.0 & 8.0 & 15.0 & 15.0 \\
\hline
\end{tabular}


World Journal of Advanced Engineering Technology and Sciences, 2021, 02(01), 034-044
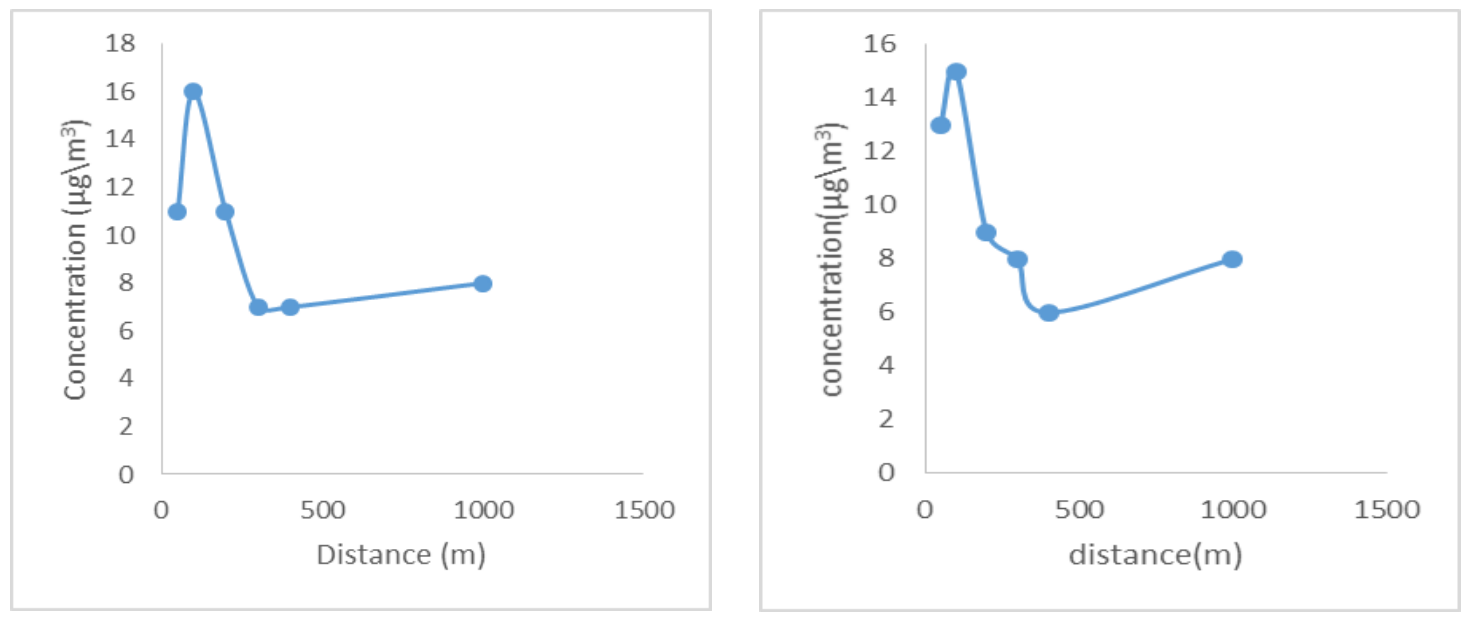

Figure 7 Plot of SPM1 against Distance Day One (Morning and Night)

The plot shows least concentration of SPM1 at $400 \mathrm{~m}$, and it was observed that $100 \mathrm{~m}$ has the highest concentration of SPM1. Also, it can be deduced that there was concentration decline from $100 \mathrm{~m}$ to $400 \mathrm{~m}$ for morning session. In addition, highest concentration level of SPM 1 at $100 \mathrm{~m}$ and lowest level of concentration was observed at $400 \mathrm{~m}$ and $1000 \mathrm{~m}$ respectively. Thus, the plot shows a random concentration of SPM 1 with distance.
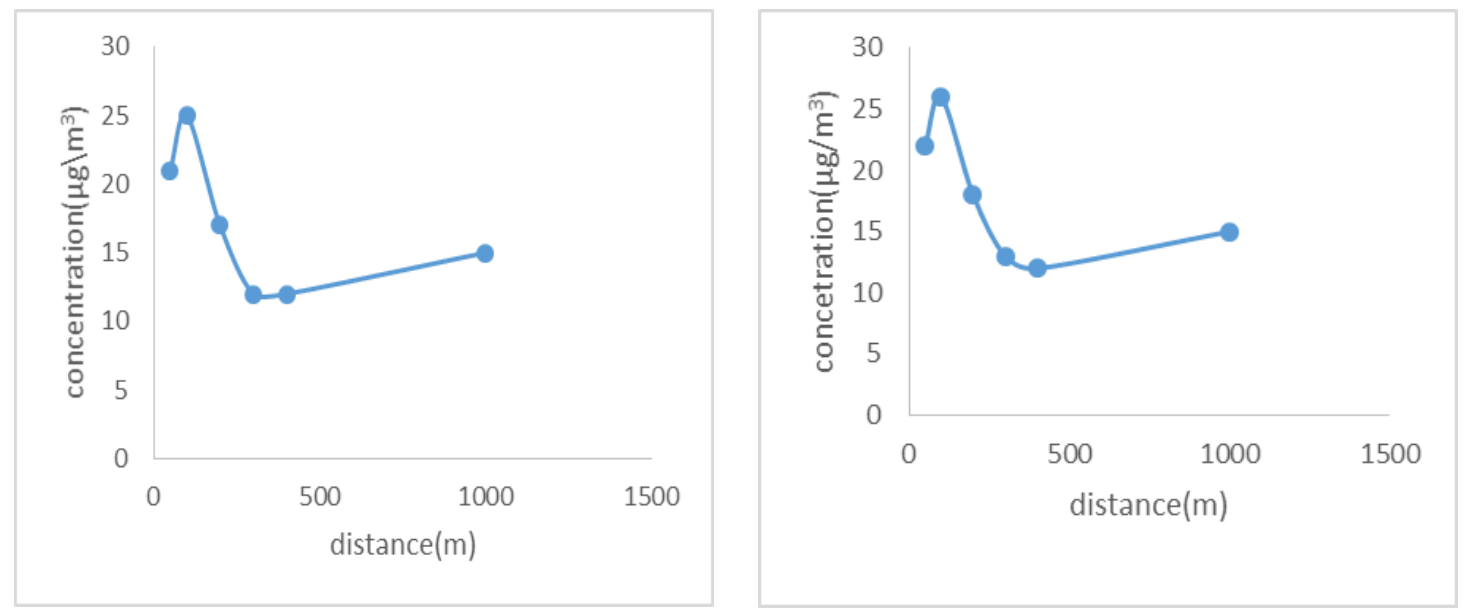

Figure 8 Plot of SPM2.5 against Distance Day One (Morning and Night)

The plot shows high level of concentration of SPM 2.5 at $100 \mathrm{~m}$ and random decline of concentration till $1000 \mathrm{~m}$. At $1000 \mathrm{~m}$, which is the farthest distance there was an increase in SPM 2.5 concentration but still lower than $100 \mathrm{~m}$ distance for morning analysis. Furthermore, night analysis plot yields random decline in concentration level and lowest at $400 \mathrm{~m}$ and highest concentration level at $100 \mathrm{~m}$. Thus, it can be seen that $1000 \mathrm{~m}$ have high level of concentration level of SPM 2.5 than $400 \mathrm{~m}$ location 
World Journal of Advanced Engineering Technology and Sciences, 2021, 02(01), 034-044
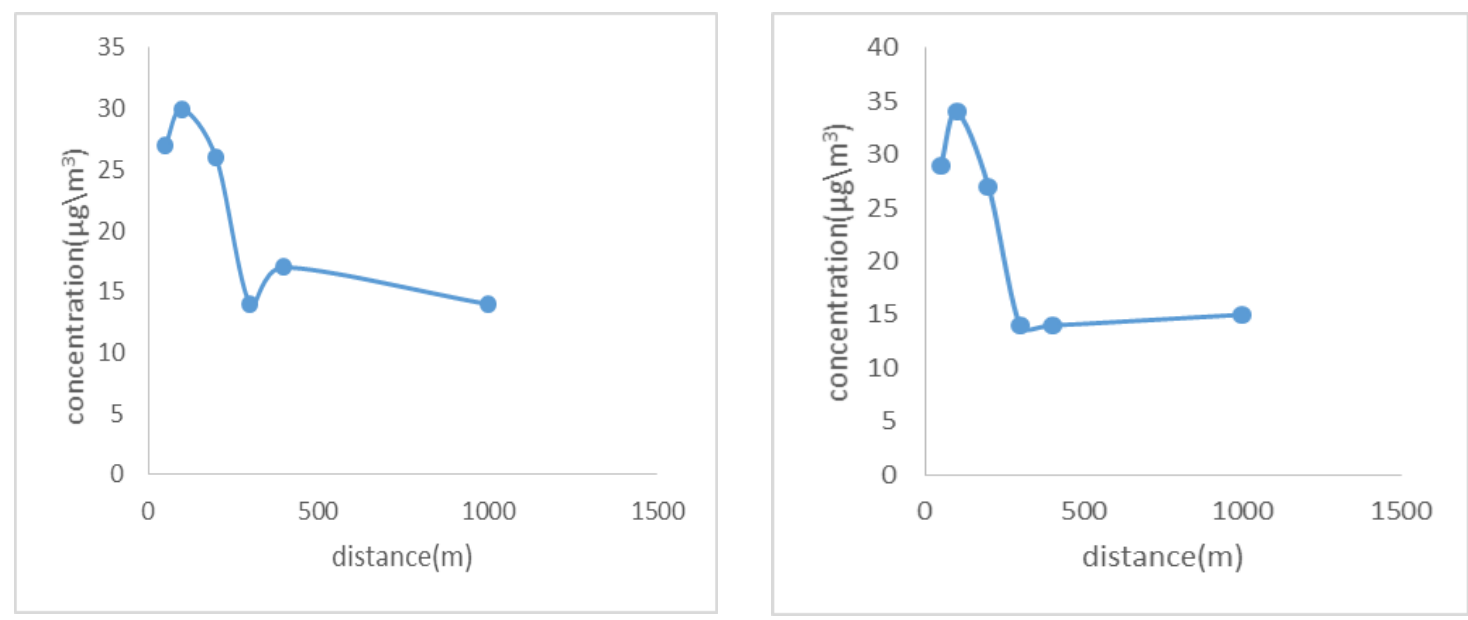

Figure 9 Plot of SPM10 against Distance Day One (Morning and Night)

The plot shows random variations of SPM 10 concentration level across the whole distance with highest concentration level observed at $100 \mathrm{~m}$ for morning and night session respectively. The least concentration level was observed at $300 \mathrm{~m}$ and $1000 \mathrm{~m}$ for morning and $300 \mathrm{~m}$ and $400 \mathrm{~m}$ for night session respectively.

Table 6 Suspended Particulate Matters for Day 2

\begin{tabular}{|l|l|l|l|l|l|l|}
\hline \multirow{2}{*}{ Location (m) } & \multicolumn{3}{|l|}{ Morning $\left(\boldsymbol{\mu g} / \mathbf{m}^{3}\right)$} & \multicolumn{3}{l|}{ Night $\left(\boldsymbol{\mu g} / \mathbf{m}^{3}\right)$} \\
\cline { 2 - 7 } & PM 1 & PM 2.5 & PM 10 & PM 1 & PM 2.5 & PM 10 \\
\hline 50 & 12.0 & 23.0 & 26.0 & 14.0 & 22.1 & 27.0 \\
\hline 100 & 13.0 & 24.1 & 29.0 & 14.0 & 23.0 & 31.0 \\
\hline 200 & 12.0 & 20.0 & 26.0 & 13.0 & 22.0 & 25.0 \\
\hline 300 & 9.0 & 15.0 & 17.0 & 9.0 & 14.0 & 16.0 \\
\hline 400 & 6.0 & 11.0 & 17.0 & 7.0 & 12.0 & 18.0 \\
\hline 1000 & 8.0 & 11.0 & 16.0 & 7.0 & 14.0 & 16.0 \\
\hline
\end{tabular}
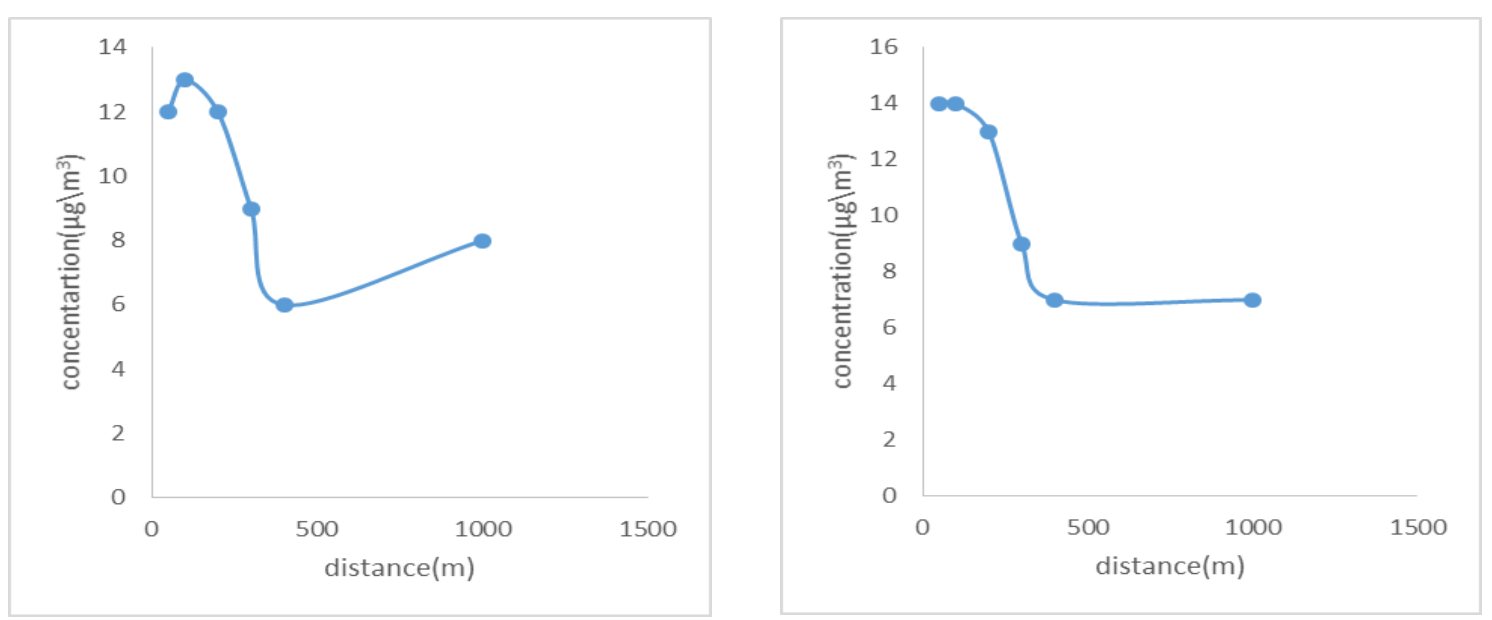

Figure 10 Plot of SPM 1 against Distance Day Two (Morning and Night) 
It can be deduced form Figure 10 that there is steady decline in PM1 concentration for day 2 morning from $100 \mathrm{~m}$ to $1000 \mathrm{~m}$. Similarly, the decline trend is also seen in day 2 night with high concentration depending on the proximity to the pollutant source as seen in morning and night session respectively.
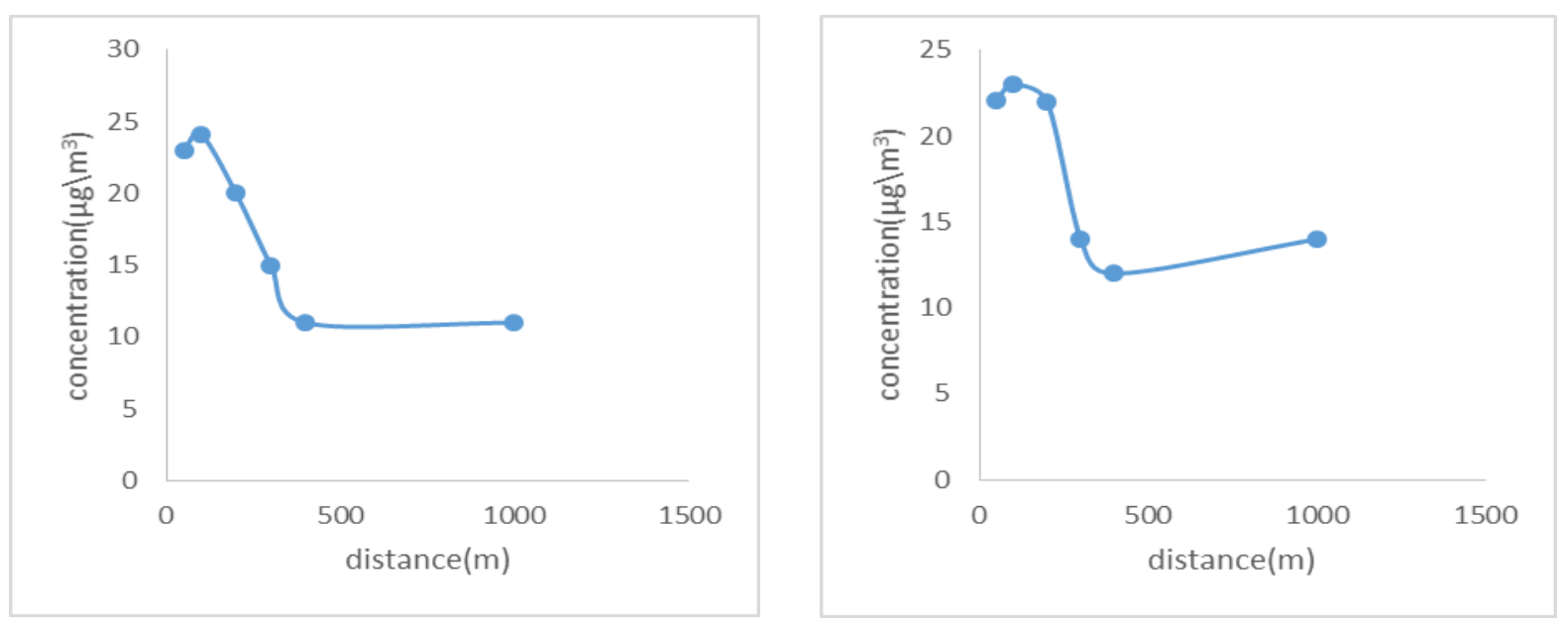

Figure 11 Plot of SPM 2.5 against Distance Day Two (Morning and Night)

The plot depicts gradual decline trend in the concentration level of PM2.5 for both morning and night session of day 2 . The particulate decline trend is such that the closest distance to pollutant source shows high level of particulate concentration
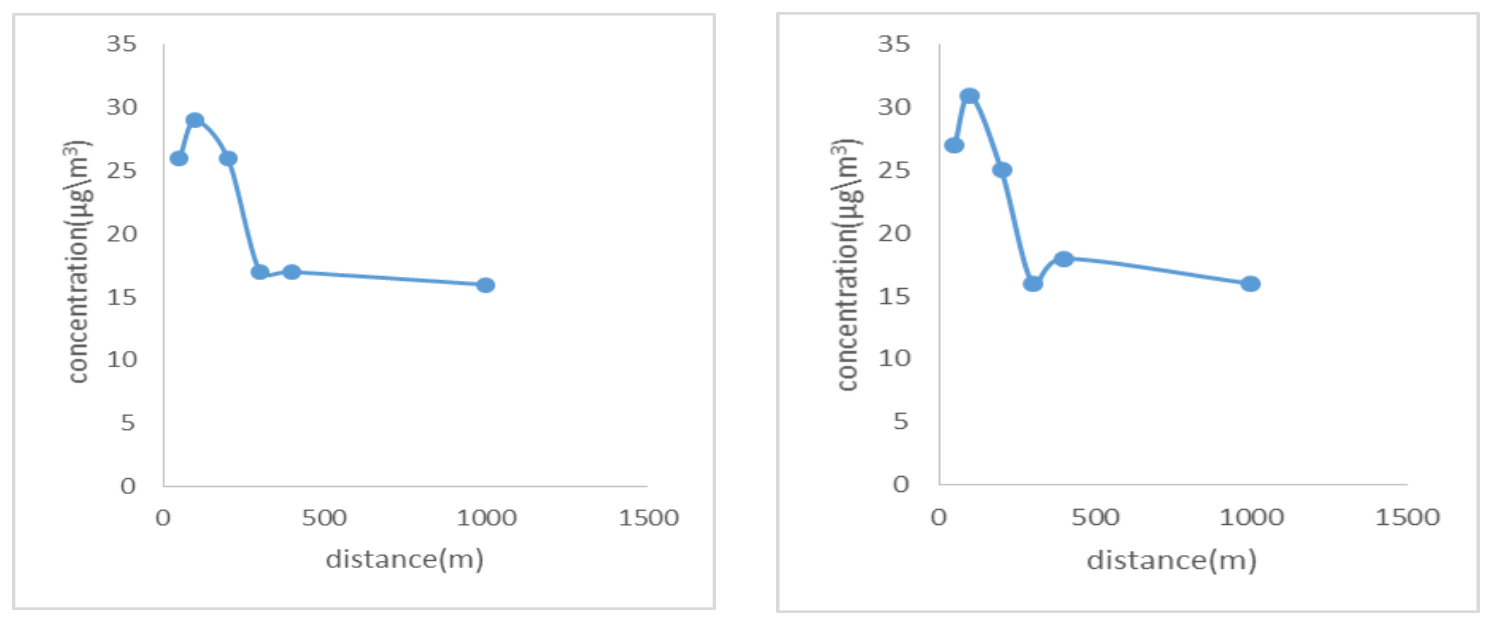

Figure 12 Plot of SPM 10 against Distance Day Two (Morning and Night)

The concentration level trend of PM 10 in day 2 morning and night shows highest level of PM 10 concentration at $100 \mathrm{~m}$ for both sessions respectively. Besides, there is gradual reduction trend in concentration level of PM 10 from $200 \mathrm{~m}$ to $1000 \mathrm{~m}$ in morning and night sessions.

Besides, experimental and model $\mathrm{SO}_{2}$ concentrations were compared to determine its deviation.

Table 7 Concentrations of Experimental and modeled values

\begin{tabular}{|l|l|l|l|l|l|l|}
\hline Experimental Value of $\mathrm{SO}_{2}\left(\mu \mathrm{g} / \mathrm{m}^{3}\right)$ & 50 & 20 & 10 & 10 & 0 & 0 \\
\hline Modeled Value of $\mathrm{SO}_{2}\left(\mu \mathrm{g} / \mathrm{m}^{3}\right)$ & 26 & 3.71 & 2.8 & 0.47 & 0.019 & 0.002 \\
\hline Deviation $(\%)$ & 41 & 16.3 & 7.2 & 9.53 & -1.9 & -0.2 \\
\hline
\end{tabular}




\section{Conclusion}

This research study has shown dispersion of pollutants in the Eagle Island area, Port Harcourt with both experimental and mathematical models analysis. This research shows high levels of concentration at farther distances from the source due to wind speed and wind directions. Conclusively, the activities of artisanal refineries have contributed to the environmental degradations and pollution of Port Harcourt city as whole with its harmful and degradation effects on the ecosystem of the city. The emissions of harmful substances like $\mathrm{NO}_{2}, \mathrm{CO}_{2}, \mathrm{CO}, \mathrm{VOC}, \mathrm{PM} 1, \mathrm{PM} 2.5$ and PM 10 have negative impacts on the environment that is now a major threat to human existence and therefore need to be regulated by supervisory agencies. The harmful products (gases) releases into the atmosphere can lead to global warming and depletion of ecosystem due to artisanal refineries activities in the Port Harcourt City environs. Thus, the environmental study for possible pollutant from artisanal refining of crude oil in Port-Harcourt using Eagle Island as a case study is of great concern due to the fact that Port-Harcourt and its environs have suffered a great deal of environmental degradation, through emission of $\mathrm{CO}_{2}$ that causes green-house effect. Hence there is need to carryout environmental audit on this areas to ascertain possible deviation from environmental standards. Thus, this study reveal that pollutant gases contained in air like $\mathrm{NO}_{2}, \mathrm{CO}_{2}$ and VOC and suspended particulate matters (PM 1, PM 2.5 and PM 10), possess no trace of environmental contaminations due to the fact that the amount of these gases and matters in the atmosphere are within the acceptable environmental requirements and standard. Hence, human and other living organisms including natural ecosystem of the study area are environmentally secured for now but there should be a routine environmental evaluation in order to determine the amount of these environmental pollutants and ensuring continuous compliance level with environmental regulators' standard to promote healthy environment. Besides, a more friendly ecosystem can be achieved by replacing artisanal refineries with modular refineries to provide needed petroleum products for the area without destroying the ecosystem.

\section{Compliance with ethical standards}

\section{Acknowledgments}

The authors sincerely thank the academic and non-academic staffs of the department of Chemical/Petrochemical Engineering, Faculty of Engineering at the Rivers State University, Port-Harcourt for their supports in carrying out this research study.

\section{Disclosure of conflict of interest}

The authors declares that there is no conflict of interest in their research study.

\section{References}

[1] Abdelrasoul AMW, AL-Hadad A, Khan AR. Oil Refineries Emissions Impact on Urban Localities using AERMOD. Amer. J. Environ. Sci. 2010; 6(6): 505-515.

[2] Ajao EA, Anurigwo S. Land-based sources of pollution in the Port Harcourt, Nigeria. Ambio J. Hum. Env. 2002; 31(5): 442-445.

[3] UNEP. Environmental Assessment of Ogoni Land. Nairobi. Kenya: United Nations Environment Programme. 2011.

[4] Idris MN. Review of Nigeria Environment through the Activities of Refining of Petroleum Product. Journal of Environment Society. 2014; 3(11): 319-330.

[5] Al-Hamad KK, Khan AR. Total Emission from Flaring in Kuwait Oil Fields. Am. J. Environ. Sci. 2008; 4: 31-38.

[6] Baltrėnas P, Baltrènaitė E, Šerevičienė V, Pereira P. Atmospheric BTEX Concentrations in the Vicinity of the Crude Oil Refinery of the Baltic Region. Environ. Monitor. Assess. 2011; 182(14): 115-127. 